\title{
Utilization of tracheostomy among geriatric trauma patients and association with mortality
}

\author{
Kjirsten Ayn Carlson ${ }^{1} \cdot$ Navpreet Kaur Dhillon ${ }^{1} \cdot$ Kavita Anil Patel ${ }^{1} \cdot$ Raymond Huang ${ }^{1} \cdot$ Phillip $_{\mathbf{~ N g}^{2}}$. \\ Daniel Reed Margulies ${ }^{1} \cdot$ Eric Jude Ley ${ }^{1} \cdot$ Galinos Barmparas ${ }^{1}$ (])
}

Received: 25 November 2018 / Accepted: 28 July 2019 / Published online: 8 August 2019

○) Springer-Verlag GmbH Germany, part of Springer Nature 2019

\begin{abstract}
Background The purpose of this study was to investigate trends in tracheostomy (TR) utilization among trauma patients over the last decade and explore its impact on mortality among elderly trauma patients.

Methods Patients 18 years or older with at least $72 \mathrm{~h}$ on the ventilator were selected from the National Trauma Databank research datasets 2007 to 2015. Patients were divided into three groups based on age: 18-60,61-80, and > 80 years and proportions of patients undergoing a TR were depicted. Elderly ( $>80$ years) were divided into two groups, based on whether they underwent a TR. The primary outcome was mortality. A Cox regression model with a time-dependent variable was utilized to account for survival bias.

Results Over the 9-year study period 284,774 patients met inclusion criteria. Of those, 21,465 (7.5\%) were older than 80 years. Elderly patients were significantly less likely to undergo a TR $(13.1 \%$ vs. $21.5 \%$ in the $18-60$ years and $20.4 \%$ in the 61-80 years group, $p<0.01)$ and this trend continued throughout the study period. Among the elderly patients, those who underwent TR were more likely to have a severe (AIS $\geq 3$ ) thoracic, abdominal, and/or spinal injury, but not head injury and were less likely to have a history of cerebrovascular accident $(5.9 \%$ vs. $7.7 \%, p<0.01)$. The overall mortality was significantly higher in elderly patients who did not undergo a TR $(46.9 \%$ vs. $17.6 \%, p<0.01)$. The adjusted hazard ratio for elderly patients undergoing a TR was 0.36 (adjusted $p<0.01$ ).

Conclusion In ventilated trauma patients, tracheostomy is less likely to be utilized in the elderly population compared to younger age groups. Amongst the elderly patients, performance of tracheostomy was associated with a significantly higher overall survival. Delaying or avoiding this procedure in the elderly trauma patient predominantly based on age might not be justified.
\end{abstract}

Study type Prognostic/epidemiological.

Level of evidence III or IV.

Keywords Elderly $\cdot$ Tracheostomy $\cdot$ Trauma $\cdot$ Outcome $\cdot$ Mortality

Abstract presented at The Academic Surgical Congress in Jacksonville, FL in January 2018 as an oral quickshot presentation.

Galinos Barmparas

Galinos.Barmparas@cshs.org

Kjirsten Ayn Carlson

Kjirsten.Carlson@cshs.org

Navpreet Kaur Dhillon

Navpreet.Dhillon@cshs.org

Kavita Anil Patel

Kavita.Patel@cshs.org

Raymond Huang

Raymond.Huang@cshs.org

Phillip Ng

Philip.Ng@cshs.org
Daniel Reed Margulies

Daniel.Margulies@cshs.org

Eric Jude Ley

Eric.Ley@cshs.org

1 Division of Acute Care Surgery and Surgical Critical Care, Department of Surgery, Cedars-Sinai Medical Center, 8635 W. 3rd Street, Suite 650W, Los Angeles, CA 90048, USA

2 Division of General Internal Medicine, Department of Medicine, Cedars-Sinai Medical Center, Los Angeles, CA, USA 


\section{Background}

The elderly population is the fastest growing population in the United States. According to the 2014 United States Census bureau, persons aged 65 and older will represent over a fifth of the world's population by 2020 [1-3]. With this substantially and rapidly growing population comes a reciprocal increase in the proportion of elderly patients admitted following a traumatic injury [3]. In fact, accidental injury is now the seventh leading cause of death within this population [4]. For those surviving their injuries, the risk of a protracted hospital stay and prolonged ventilatory support is high, prompting decisions for further interventions to improve survival and facilitate disposition. Agerelated treatment bias [5], however, in addition to personal perception of the minimally acceptable outcome may lead to unnecessary delays that in turn may impact, not only the functional outcome of these patients, but also their survival.

Percutaneous tracheostomy (TR) is a commonly performed procedure in patients requiring prolonged mechanical ventilation. Although its impact on survival remains debatable [6], it is accepted that patients with TR benefit from decreased need for sedation [7], potentially leading to decreased ventilation days, decreased risk for a ventilatorassociated pneumonia, earlier mobility and even earlier initiation of oral feeding when compared to patients without a TR [8-14]. Various factors, however, including the overall decrease in the use of TR in recent years [9], may lead to a decreased utilization of a TR in the elderly [9], possibly depriving them from these benefits and leading to a decreased survival.

The purpose of this study was twofold: (1) to explore nationwide trends in TR utilization for trauma patients over the last decade according to age and (2) to characterize the association between TR and mortality in elderly trauma patients over the age of 80 years. We hypothesized that the use of TR has been declining among all age groups, despite its association with improved survival.

\section{Methods}

The National Trauma Databank (NTDB) was queried for adult (18 years or older) patients admitted to participating trauma centers from 2007 to 2015 and who required at least $72 \mathrm{~h}$ of mechanical ventilation (MV). To minimize bias, transferred patients were excluded as procedures and interventions performed at the transferring institution were not available. In addition, patients with unknown day to TR and those undergoing a TR before hospital day 3 or after hospital day 30 were also excluded as they were considered outliers. Lastly, to avoid reporting errors, patients were excluded if the day from admission to TR exceeded the reported days of MV.

For patients who met inclusion criteria, demographics including age, sex and race and injury characteristics including Injury Severity Score (ISS), regional Abbreviated Injury Scale (AIS) scores, admission Glasgow Coma Scale (GCS) scores and admission systolic blood pressure (SBP) were reviewed. Patients undergoing a temporary tracheostomy were coded based on the International Classification of Diseases-9th Edition code 31.1. The day from admission to this procedure was also recorded. Other surgical interventions including exploratory laparotomy, thoracotomy and craniotomy/craniectomy were gathered. Comorbid conditions including cardiac disease, pulmonary disease and/or smoking, liver disease, renal disease and need for dialysis, diabetes mellitus (DM), peripheral vascular disease (PVD) and prior amputation, dementia, history of cerebrovascular accident (CVA), bleeding disorder and functional dependency were included. Also included was the Do Not Resuscitate (DNR) status.

\section{Statistical analysis}

\section{Trends in TR utilization among age groups}

The study cohort was divided into three groups based on age: $18-60$ years, $61-80$ years, and $>80$ years. The overall annual proportion of patients undergoing a TR was explored among these age groups and a trend analysis was performed utilizing a linear regression model. A $p$ value of $<0.05$ was considered statistically significant. Trends in TR utilization were also explored within subgroups of patients including those with isolated traumatic brain injuries (TBI), defined as AIS head $>2$ with all other regional AIS $<3$ and those with over 10 and 15 ventilation days.

\section{Comparison of patients who underwent a TR according to age group}

Patients who underwent a TR were then selected and were compared with regard to demographics, injury characteristics, procedures performed and comorbidities according to the above age groups. Comparisons were made utilizing analysis of variance (ANOVA).

\section{Comparison of elderly patients ( $>80$ years) according to whether they underwent a TR or not}

The subgroup of elderly patients ( $>80$ years) was then divided into those who underwent a TR and those who did not. The two groups were compared for differences in 
baseline demographics and injury characteristics. Chi-square test was used for proportions and $t$ test was used for means. The primary outcome was in-hospital 30-day mortality. A Kaplan-Meier survival curve with log-rank test was used to compare the outcome. A Cox regression model utilizing a time-dependent variable and incorporating all confounding factors was used to calculate the adjusted hazard ratio (AHR) and $95 \%$ confidence interval (CI). This model was used to account for survival bias of patients undergoing a TR due to higher probability of survival.

Analyses were performed using the IBM SPSS Statistics for Windows, Version 24.0 (Armonk, NY; IBM Corp.). This study was exempt from an Institutional Review Board approval.

\section{Results}

Over the 9-year study period, there were 6,753,862 entries in the NTDB. Of those, 308,061(4.6\%) met the study's initial inclusion criteria. A total of 23,287 (7.6\%) patients however, were subsequently excluded due to either having a TR performed before hospital day 3 or after day 30 , or because the day to TR exceeded the days of MV or lastly, because the day to TR was not reported. This left 284,774 patients for analysis, with 58,825 (20.7\%) undergoing a TR (Fig. 1).
Overall, the median age of the entire population was 49 years, with $73.7 \%$ being male. The median GCS was 11 on admission and the median ISS was 22 . The majority ( $n=198,671$ or $69.8 \%)$ were between 18 and 60 years, $22.7 \%(n=64,638)$ were between 61 and 80 years, and the remaining $7.5 \%(n=21,465)$ comprised the elderly population ( $>80$ years). TR was performed on $21.5 \%(n=42,811)$, $20.4 \%(n=13,210)$ and $13.1 \%(n=2804)$ respectively $(p<0.001)$. Figure 2 depicts the trends in TR utilization during the study period according to age group. Overall, there was a trend towards decreased proportion of patients undergoing a TR during the study period and this was noted among all age groups (Fig. 2a). The proportion of elderly (> 80 years) undergoing a TR was consistently lower than that observed among the other two age groups throughout the study period. This was also noted among patients with isolated TBI (Fig. 2b). The same trend was observed for patients who required a minimum of 10 (Fig. 2c) and 15 (Fig. 2d) ventilation days; however, the differences between age groups decreased with increasing ventilation days.

Table 1 depicts the demographics and injury characteristics of patients undergoing a TR based on age group. Compared to patients between 18 and 60 years and those between 61 and 80 years, elderly patients ( $>80$ years) were significantly less likely to be admitted with a GCS of 3 ( $16.2 \%$ vs. $43.8 \%$ vs. $25.7 \%, p<0.001)$. Their injury burden was overall lower with a significantly lower ISS
Fig. 1 Study outline. $N T D B$ National Trauma Data Bank, $T R$ Tracheostomy. * Inclusion criteria: 1 . Age $\geq 18$ (y) 2. Mechanical ventilation $>2$ days 3 . Index admission (not a transfer)

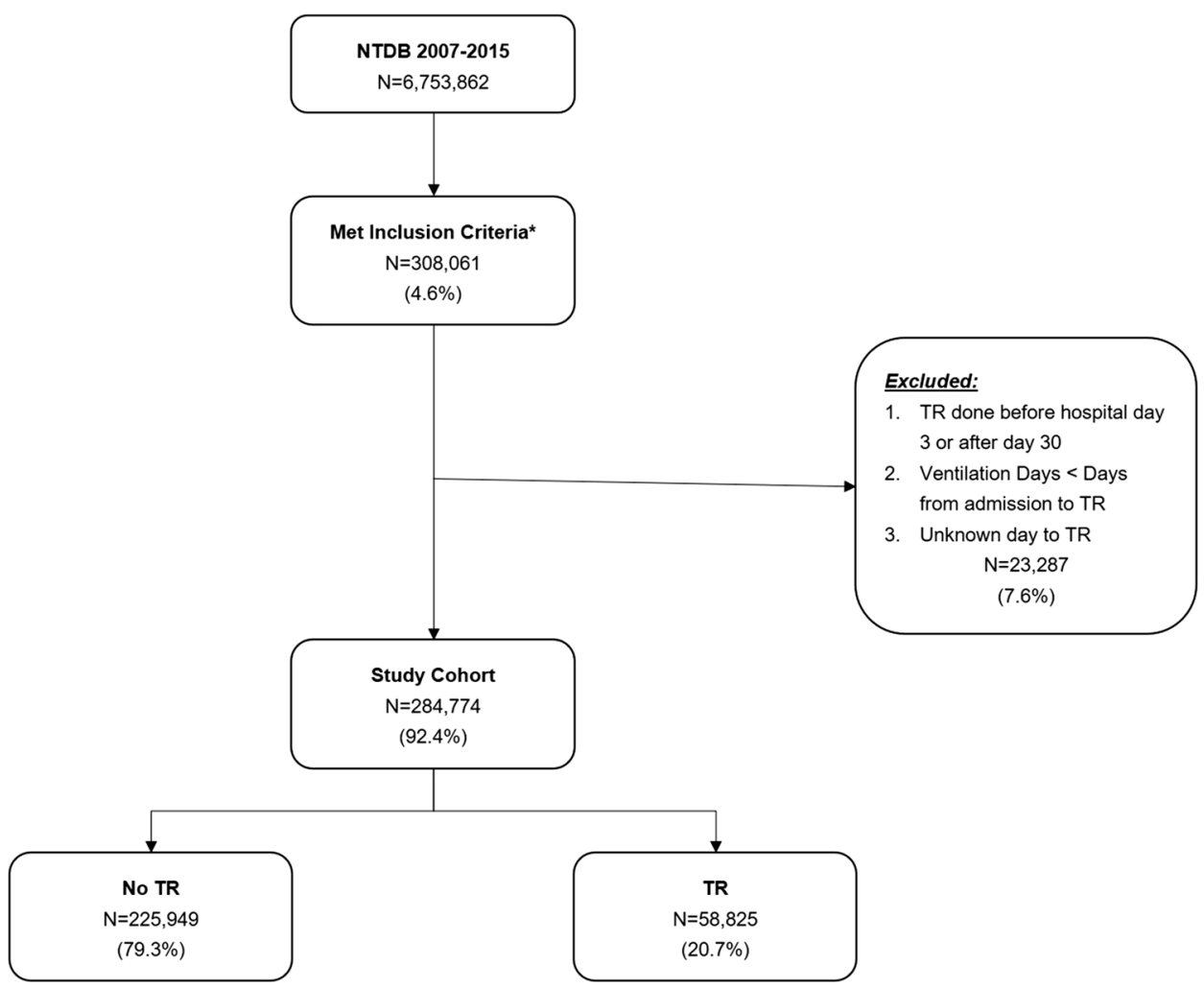






Fig. 2 Proportion of patients undergoing a TR per year according to age group for all patients (a), patients with isolated TBI (b), patients with aminimum of 10 ventilation days (c), and patients with a minimum of 15 ventilation days (d). TR Tracheostomy, TBI Traumatic

and a significantly lower proportion with severe (AIS $\geq 3$ ), chest, or abdominal injuries (Table 1). However, they were significantly more likely to have an underlying cardiac disease $(16.0 \%$ vs. $1.6 \%$ vs. $10.6 \%, p<0.001)$ and/or a bleeding disorder $(18.5 \%$ vs. $2.1 \%$ vs. $11.7 \%, p<0.001)$ (Table 1 ). The elderly group ( $>80$ years) was significantly less likely to have an underlying pulmonary disease and/or a smoking history ( $14.6 \%$ vs. $19.7 \%$ vs. $21.4 \%, p<0.001)$. The median duration on the ventilator prior to TR was 9 days for patients 18-60 years, but was significantly higher for patients between $61-80$ years and $>80$ years (median of 10 days for both, $p<0.001$ ) (Table 1).

Elderly patients were then compared according to whether they underwent a TR or not (Table 2). Those undergoing a TR were equally likely to be admitted with a GCS of $3(16.2 \%$ vs. $16.9 \%, p=0.418)$ and to undergo a craniotomy/craniectomy $(3.7 \%$ vs. $3.4 \%, p=0.363)$. However, they were significantly more likely to have a severe (AIS $\geq 3$ ) thoracic, abdominal and/or spinal injury, but not head injury (Table 2). Lastly, TR patients were significantly less likely to be functionally dependent $(2.9 \%$ vs. $4.3 \%, p=0.001)$, have a history of CVA $(5.9 \%$ vs. $7.7 \%, p=0.001)$ and have a DNR status $(3.5 \%$ vs. $6.6 \%$, $p<0.001$ ) (Table 2).
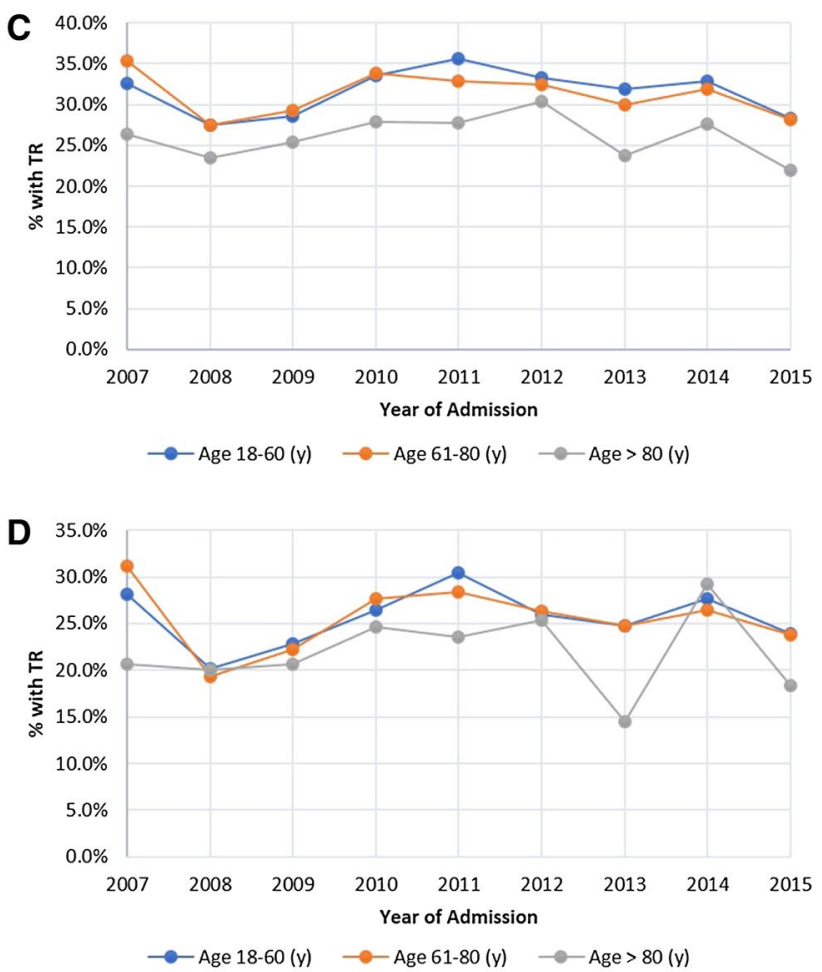

Brain Injury. Isolated TBI was defined as Abbreviated Injury Scale Score (AIS) for head $\geq 3$ with all other regional AIS $<3$. $P$ value for all trends $<0.001 . P$ value was extracted from a linear regression model

The overall mortality for this subset of patients was $43.1 \%$ $(n=9119): 17.6 \%(n=485)$ for those who underwent a TR and $46.9 \%(n=8634)$ for those that did not. Figure 3 depicts the Kaplan-Meier survival curve for the 30-day mortality among the two cohorts. A proportional Cox regression model with a time dependent variable adjusting for sex, admission SB $p<90 \mathrm{mmHg}$, admission GCS, ISS, exploratory laparotomy, cardiac disease, renal disease and/or dialysis, functional dependency, dementia, DNR, history of CVA and bleeding disorder demonstrated an AHR of 0.36 (95\% CI 0.32, 0.40), adjusted $p<0.001$ (Fig. 3).

\section{Discussion}

Over a 9-year study period ending in 2015, the use of TR for trauma patients has had a declining trend among all age groups. Elderly trauma patients ( $>80$ years) were significantly less likely to undergo a TR, and when they did, this occurred in a delayed fashion when compared to younger patients. The adjusted survival benefit for elderly patients undergoing a TR was profound, reaching approximately $75 \%$. This finding likely indicates appropriate selection of patients for this procedure and definitely an association 
Table 1 Comparison of demographics and injury characteristics of patients undergoing a tracheostomy (TR) according to age group

\begin{tabular}{|c|c|c|c|c|c|}
\hline & Total $(n=58,825)$ & $\begin{array}{l}\text { Age } 18-60 \text { (years) } \\
(n=42,811)\end{array}$ & $\begin{array}{l}\text { Age } 61-80 \text { (years) } \\
(n=13,210)\end{array}$ & $\begin{array}{l}\text { Age }>80(\text { years }) \\
(n=2804)\end{array}$ & $p$ value \\
\hline Male & $75.4 \%(44,187 / 58,634)$ & $78.3 \%(33,413 / 42,668)$ & $69.5 \%(9159 / 13,178)$ & $57.9 \%(1615 / 2788)$ & $<0.001$ \\
\hline \multicolumn{6}{|l|}{ Race } \\
\hline White & $71.7 \%(40,793 / 56,859)$ & $67.9 \%(28,144 / 41,422)$ & $81.2 \%(10,348 / 12,738)$ & $85.3 \%(2301 / 2699)$ & $<0.001$ \\
\hline Black & $15.5 \%(8813 / 56,859)$ & $17.8 \%(7392 / 41,422)$ & $9.7 \%(1239 / 12,738)$ & $6.7 \%(182 / 2699)$ & $<0.001$ \\
\hline Hispanic/Latino & $8.0 \%(4575 / 56,859)$ & $9.3 \%(3854 / 41,422)$ & $4.8 \%(615 / 12,738)$ & $3.9 \%(106 / 2699)$ & $<0.001$ \\
\hline Asian & $1.3 \%(735 / 56,859)$ & $1.1 \%(457 / 41,422)$ & $1.7 \%(222 / 12,738)$ & $2.1 \%(56 / 2699)$ & $<0.001$ \\
\hline Other & $3.4 \%(1943 / 56,859)$ & $3.8 \%(1575 / 41,422)$ & $2.5 \%(314 / 12,738)$ & $2.0 \%(54 / 2699)$ & $<0.001$ \\
\hline $\begin{array}{l}\text { Admission SBP mmHg, } \\
\text { Mean (SD) [median] }\end{array}$ & $131.3(35.3)[131.0]$ & $129.1(34.3)$ [130.0] & $136.0(37.1)[136.0]$ & $142.7(38.1)$ [142.0] & $<0.001$ \\
\hline $\mathrm{SB} p<90 \mathrm{mmHg}$ & $10.6 \%(6087 / 57,575)$ & $11.0 \%(4592 / 41,889)$ & $9.9 \%(1283 / 12,953)$ & $78 \%(212 / 2733)$ & $<0.001$ \\
\hline $\begin{array}{l}\text { Admission GCS, mean } \\
\text { (SD) [median] }\end{array}$ & $8.5(5.3)[7.0]$ & $7.8(5.1)[6.0]$ & $10.4(5.1)[14.0]$ & $11.7(4.6)[14.0]$ & $<0.001$ \\
\hline $\mathrm{GCS}=3$ & $38.5 \%(21,862 / 56,833)$ & $43.8 \%(18,171 / 41,508)$ & $25.7 \%(3257 / 12,653)$ & $16.2 \%(434 / 2672)$ & $<0.001$ \\
\hline $\mathrm{GCS} \leq 8$ & $53.3 \%(30,282 / 56,833)$ & $60.2 \%(25,008 / 41,508)$ & $36.5 \%(4614 / 12,653)$ & $24.7 \%(660 / 2672)$ & $<0.001$ \\
\hline $\mathrm{GCS}=15$ & $27.3 \%(15,504 / 56,833)$ & $22.1 \%(9156 / 41,508)$ & $40.1 \%(5076 / 12,653)$ & $47.6 \%(1272 / 2672)$ & $<0.001$ \\
\hline ISS, mean (SD) [median] & $26.4(12.6)[25.0]$ & $27.9(12.7)[26.0]$ & $23.0(11.8)[22.0]$ & $20.3(10.8)[18.0]$ & $<0.001$ \\
\hline ISS $<16$ & $16.8 \%(9572 / 57,087)$ & $13.6 \%(5640 / 41,521)$ & $23.7 \%(3048 / 12,847)$ & $32.5 \%(884 / 2719)$ & $<0.001$ \\
\hline ISS $16-25$ & $33.9 \%(19,363 / 57,087)$ & $31.9 \%(13,242 / 41,521)$ & $39.2 \%(5034 / 12,847)$ & $40.0 \%(1087 / 2719)$ & $<0.001$ \\
\hline ISS $>25$ & $49.3 \%(28,152 / 57,087)$ & $54.5 \%(22,639 / 41,521)$ & $37.1 \%(4765 / 12,847)$ & $27.5 \%(748 / 2719)$ & $<0.001$ \\
\hline $\begin{array}{l}\text { AIS head, mean (SD) } \\
\text { [median] }\end{array}$ & $2.5(2.3)[3.0]$ & $2.6(2.3)[4.0]$ & $2.2(2.1)[2.0]$ & $2.0(2.1)[2.0]$ & $<0.001$ \\
\hline$\geq 3$ & $55.3 \%(32,524 / 58,825)$ & $57.7 \%(24,706 / 42,811)$ & $49.4 \%(6520 / 13,210)$ & $46.3 \%(1298 / 2804)$ & $<0.001$ \\
\hline $\begin{array}{l}\text { AIS neck, mean (SD) } \\
\text { [median] }\end{array}$ & $0.07(0.43)[0.0]$ & $0.09(0.48)[0.0]$ & $0.03(0.28)[0.0]$ & $0.01(0.16)[0.0]$ & $<0.001$ \\
\hline$\geq 3$ & $1.9 \%(1106 / 58,825)$ & $2.3 \%(1005 / 42,811)$ & $0.7 \%(97 / 13,210)$ & $0.1 \%(4 / 2804)$ & $<0.001$ \\
\hline $\begin{array}{l}\text { AIS face, mean (SD) } \\
\text { [median] }\end{array}$ & $0.58(0.72)[0.0]$ & $0.62(0.74)[0.0]$ & $0.45(0.64)[0.0]$ & $0.43(0.61)[0.0]$ & $<0.001$ \\
\hline$\geq 3$ & $0.5 \%(277 / 58,825)$ & $0.6 \%(241 / 42,811)$ & $0.2 \%(33 / 13,210)$ & $0.1 \%(3 / 2804)$ & $<0.001$ \\
\hline $\begin{array}{l}\text { AIS chest, mean (SD) } \\
\text { [median] }\end{array}$ & $1.7(1.7)[2.0]$ & $1.8(1.7)[2.0]$ & $1.6(1.7)[1.0]$ & $1.4(1.7)[0.0]$ & $<0.001$ \\
\hline$\geq 3$ & $46.5 \%(27,362 / 58,825)$ & $48.7 \%(20,868 / 42,811)$ & $41.8 \%(5528 / 13,210)$ & $34.5 \%(966 / 2804)$ & $<0.001$ \\
\hline AIS abdomen & $0.72(1.3)[0.0]$ & $0.80(1.3)[0.0]$ & $0.54(1.1)[0.0]$ & $0.43(1.0)[0.0]$ & $<0.001$ \\
\hline$\geq 3$ & $12.1 \%(7120 / 58,825)$ & $13.6 \%(5843 / 42,811)$ & $8.2 \%(1086 / 13,210)$ & $6.8 \%(191 / 2804)$ & $<0.001$ \\
\hline $\begin{array}{l}\text { AIS upper extremity, } \\
\text { mean (SD) [median] }\end{array}$ & $0.68(0.96)[0.0]$ & $0.71(0.98)[0.0]$ & $0.63(0.92)[0.0]$ & $0.56(0.87)[0.0]$ & $<0.001$ \\
\hline$\geq 3$ & $3.6 \%(2130 / 58,825)$ & $4.1 \%(1738 / 42,811)$ & $2.5 \%(334 / 13,210)$ & $2.1 \%(58 / 2804)$ & $<0.001$ \\
\hline $\begin{array}{l}\text { AIS lower extremity, } \\
\text { mean (SD) [median] }\end{array}$ & $0.84(1.2)[0.0]$ & $0.86(1.2)[0.0]$ & $0.79(1.2)[0.0]$ & $0.77(1.2)[0.0]$ & $<0.001$ \\
\hline$\geq 3$ & $18.2 \%(10,696 / 58,825)$ & $18.8 \%(8033 / 42,811)$ & $16.6 \%(2193 / 13,210)$ & $16.8 \%(470 / 2804)$ & $<0.001$ \\
\hline $\begin{array}{l}\text { AIS spine, mean (SD) } \\
\text { [median] }\end{array}$ & $1.1(1.5)[0.0]$ & $1.1(1.5)[0.0]$ & $1.1[1.4](0.0)$ & $1.1(1.3)[0.0]$ & $<0.001$ \\
\hline$\geq 3$ & $11.5 \%(6764 / 58,825)$ & $12.0 \%(5153 / 42,811)$ & $1.4 \%(1372 / 13,210)$ & $8.5 \%(239 / 2804)$ & $<0.001$ \\
\hline Exploratory laparotomy & $6.5 \%(3845 / 58,825)$ & $7.4 \%(3153 / 42,811)$ & $4.4 \%(585 / 13,210)$ & $3.8 \%(107 / 2804)$ & $<0.001$ \\
\hline Thoracotomy & $0.9 \%(536 / 58,825)$ & $1.1 \%(454 / 42,811)$ & $0.5 \%(72 / 13,210)$ & $0.4 \%(10 / 2804)$ & $<0.001$ \\
\hline Craniotomy/craniectomy & $5.7 \%(3378 / 58,825)$ & $6.4 \%(2761 / 42,811)$ & $3.9 \%(512 / 13,210)$ & $3.7 \%(105 / 2804)$ & $<0.001$ \\
\hline Comorbid conditions & & & & & $<0.001$ \\
\hline Cardiac disease & $4.4 \%(2522 / 56,778)$ & $1.7 \%(705 / 41,043)$ & $10.6 \%(1377 / 12,985)$ & $16.0 \%(440 / 2750)$ & $<0.001$ \\
\hline $\begin{array}{l}\text { Pulmonary disease/ } \\
\text { smoker }\end{array}$ & $19.8 \%(11,261 / 56,778)$ & $19.7 \%(8084 / 41,043)$ & $21.4 \%(2775 / 12,985)$ & $14.6 \%(402 / 2750)$ & $<0.001$ \\
\hline Liver disease & $1.0 \%(555 / 56,778)$ & $0.9 \%(379 / 41,043)$ & $1.2 \%(162 / 12,985)$ & $0.5 \%(14 / 2750)$ & $<0.001$ \\
\hline Renal disease/dialysis & $0.7 \%(409 / 56,778)$ & $0.4 \%(176 / 41,043)$ & $1.6 \%(202 / 12,985)$ & $1.1 \%(31 / 2750)$ & $<0.001$ \\
\hline
\end{tabular}


Table 1 (continued)

\begin{tabular}{|c|c|c|c|c|c|}
\hline & Total $(n=58,825)$ & $\begin{array}{l}\text { Age } 18-60 \text { (years) } \\
(n=42,811)\end{array}$ & $\begin{array}{l}\text { Age } 61-80 \text { (years) } \\
(n=13,210)\end{array}$ & $\begin{array}{l}\text { Age }>80 \text { (years) } \\
(n=2804)\end{array}$ & $p$ value \\
\hline Diabetes mellitus & $12.9 \%(7304 / 56,778)$ & $7.6 \%(3126 / 41,043)$ & $27.1 \%(3517 / 12,985)$ & $24.0 \%(661 / 2750)$ & $<0.001$ \\
\hline PVD/amputation & $0.3 \%(161 / 56,778)$ & $0.1 \%(51 / 41,043)$ & $0.7 \%(89 / 12,985)$ & $0.8 \%(21 / 2750)$ & $<0.001$ \\
\hline Functionally dependent & $1.1 \%(650 / 56,778)$ & $0.8 \%(309 / 41,043)$ & $2.0 \%(261 / 12,985)$ & $2.9 \%(80 / 2750)$ & $<0.001$ \\
\hline Dementia & $0.6 \%(313 / 56,778)$ & $0.1 \%(27 / 41,043)$ & $1.2 \%(156 / 12,985)$ & $4.7 \%(130 / 2750)$ & $<0.001$ \\
\hline CVA & $2.3 \%(1331 / 56,778)$ & $1.3 \%(541 / 41,043)$ & $4.8 \%(629 / 12,985)$ & $5.9 \%(161 / 2750)$ & $<0.001$ \\
\hline Bleeding disorder & $5.1 \%(2901 / 56,778)$ & $2.1 \%(873 / 41,043)$ & $11.7 \%(1518 / 12,985)$ & $18.5 \%(510 / 2750)$ & $<0.001$ \\
\hline DNR & $0.8 \%(443 / 56,778)$ & $0.3 \%(142 / 41,043)$ & $1.6 \%(204 / 12,985)$ & $3.5 \%(97 / 2750)$ & $<0.001$ \\
\hline $\begin{array}{l}\text { Ventilation days prior } \\
\text { to TR, Mean (SD) } \\
\text { [Median] }\end{array}$ & $10.0(5.0)[9.0]$ & $9.9[5.0](9.0)$ & $10.4(5.0)[10.0]$ & $10.4(4.7)[10.0]$ & $<0.001$ \\
\hline
\end{tabular}

$p$ values were obtained from analysis of variance (ANOVA)

$S B P$ systolic blood pressure, $S D$ standard deviation; GCS Glasgow Coma Scale; ISS Injury Severity Score; AIS Abbreviated Injury Scale; PVD peripheral vascular disease; $C V A$ cerebrovascular accident; $D N R$ do not resuscitate

between a TR and survival, rather than cause and effect phenomenon. Nonetheless, based on these results it appears that even in the elderly trauma patients who are at the highest risk for morbidity and mortality, TR should be utilized liberally and early when criteria are met. Delaying or even avoiding this intervention in this population may be associated with a higher mortality.

The discrepancy of TR utilization between the elderly trauma patients and the younger age groups could be due to age-related treatment bias: a concept related to "ageism". Clinicians may be less inclined to perform TRs in this advanced age group in order to avoid "unnecessary procedures" in patients they deem to have a shortened life span. However, physicians commonly make inaccurate predictions on the life expectancy of critically ill patients [15] and thus this judgment may not be justified.

Brandberg et al. surveyed treatment and mortality for critically ill patients aged $>65$ in a general intensive care unit (ICU) and divided patients into two groups based on age: 65-79 years and $>80$ years [16]. They found that patients in the older group ( $>80$ years) received less treatments and obtained more limitations in life-sustaining treatments compared to those 65-79 years, despite adjusting for severity of illness and comorbidity.

Previous studies have also examined outcomes of critically ill patients based on age [17-23]. The common finding amongst these studies was that age alone should not preclude patients from undergoing advanced therapies in the intensive care setting. Specifically, de Rooj et al. concluded that even though ICU mortality was higher in elderly patients, high age alone was not responsible for poorer outcomes, but premorbid functional status and severity of illness was the main contributor [18]. However, no study to knowledge has focused on TR utilization in the aging trauma population.
The present study demonstrates that TR is associated with a significant survival benefit in the elderly trauma population. This improved outcome could be due to the aforementioned benefits of TR, especially those that are of greatest concern for elderly patients; early mobility and initiation of feeding, decreased use of sedatives and decreased incidence of ICU delirium. For ICU delirium specifically, when encountered in the elderly population, it is usually associated with a worse overall prognosis and even increased hospital mortality [24].

Age alone should not be the sole predeterminant for the decision to perform additional interventions on elderly patients, including a TR. The association of improved survival with TR in elderly trauma patients indicates a significant role for this procedure when criteria are met. In the elderly, in addition to the standard criteria, other might include patient's and family's wishes for goals of care, underlying functional status, comorbid conditions and overall prognosis. Early identification of patient's who might benefit from a TR is important as unnecessary delays may result in increased mortality risk. Discussing the benefits of this temporary intervention and alleviating the potential image perceptions and possible impact on quality of life might be helpful. This discussion could even be held in the primary care setting when establishing advanced directives so that patients and family members can make an informed decision prior to the fact.

Our findings should be interpreted with caution. Despite our large sample size, the source of our data, the NTDB, may contain reporting errors and missing data. Selection bias could not be accounted for as patients with worse clinical status might not have qualified for a TR, based on variables not included in this study or in the NTDB. Patient wishes for goals of care were not included. We attempted to account for the survival bias by utilizing a Cox regression with a 
Table 2 Comparison of demographics and injury characteristics of elderly patients ( $>80$ years) based on whether they underwent a tracheostomy (TR) or not

\begin{tabular}{|c|c|c|c|c|}
\hline & Total $(n=21,465)$ & Tracheostomy $(n=2804)$ & No tracheostomy $(n=18,661)$ & $p$ value \\
\hline Age (years), mean (SD) [median] & $84.9(3.1)[84.0]$ & $84.5(3.1)[84.0]$ & $85.0(3.1)[85.0]$ & $<0.001$ \\
\hline Male & $55.2 \%(11,801 / 21,396)$ & $57.9 \%(1615 / 2788)$ & $54.7 \%(10,186 / 18,608)$ & 0.002 \\
\hline \multicolumn{5}{|l|}{ Race } \\
\hline White & $86.9 \%(17,966 / 20,681)$ & $85.3 \%(2301 / 2699)$ & $87.1 \%(15,665 / 17,982)$ & 0.008 \\
\hline Black & $5.0 \%(1041 / 20,681)$ & $6.7 \%(182 / 2699)$ & $4.8 \%(859 / 17,982)$ & $<0.001$ \\
\hline Hispanic/Latino & $3.6 \%(745 / 20,681)$ & $3.9 \%(106 / 2699)$ & $3.6 \%(639 / 17,982)$ & 0.331 \\
\hline Asian & $2.5 \%(513 / 20,681)$ & $2.1 \%(56 / 2699)$ & $2.5 \%(457 / 17,982)$ & 0.146 \\
\hline Other & $2.0 \%(416 / 20,681)$ & $2.0 \%(54 / 2699)$ & $2.0 \%(362 / 17,982)$ & 0.966 \\
\hline Admission SBP mmHg, mean (SD) [median] & $145.5(36.4)[145.0]$ & $142.7(38.1)[142.0]$ & $146.0(36.1)[146.0]$ & $<0.001$ \\
\hline $\mathrm{SB} p<90 \mathrm{mmHg}$ & $5.8 \%(1219 / 20,937)$ & $7.8 \%(212 / 2733)$ & $5.5 \%(1007 / 18,204)$ & $<0.001$ \\
\hline Admission GCS, mean (SD) [median] & $11.5(4.7)[14.0]$ & $11.7(4.6)[14.0]$ & $11.4(4.7)[14.0]$ & 0.009 \\
\hline $\mathrm{GCS}=3$ & $16.8 \%(3395 / 20,223)$ & $16.2 \%(434 / 2672)$ & $16.9 \%(2961 / 17,551)$ & 0.418 \\
\hline $\mathrm{GCS} \leq 8$ & $26.9 \%(5436 / 20,223)$ & $24.7 \%(660 / 2672)$ & $27.2 \%(4776 / 17,551)$ & 0.006 \\
\hline $\mathrm{GCS}=15$ & $46.1 \%(9331 / 20,223)$ & $47.6 \%(1272 / 2672)$ & $45.9 \%(8059 / 17,551)$ & 0.103 \\
\hline ISS, mean (SD) [median] & $18.2(10.5)[17.0]$ & $20.3(10.8)[18.0]$ & $17.8(10.5)[17.0]$ & $<0.001$ \\
\hline ISS $<16$ & $41.5 \%(8554 / 20,636)$ & $32.5 \%(884 / 2719)$ & $42.8 \%(7670 / 17,917)$ & $<0.001$ \\
\hline ISS $16-25$ & $36.7 \%(7570 / 20,636)$ & $40.0 \%(1087 / 2719)$ & $36.2 \%(6483 / 17,917)$ & $<0.001$ \\
\hline ISS $>25$ & $21.9 \%(4512 / 20,636)$ & $27.5 \%(748 / 2719)$ & $21.0 \%(3764 / 17,917)$ & $<0.001$ \\
\hline AIS head, mean (SD) [median] & $2.2(2.1)[3.0]$ & $2.0(2.1)[2.0]$ & $2.3(2.1)[3.0]$ & $<0.001$ \\
\hline$\geq 3$ & $50.4 \%(10,829 / 21,465)$ & $46.3 \%(1298 / 2804)$ & $51.1 \%(9531 / 18,661)$ & $<0.001$ \\
\hline AIS neck, mean (SD) [median] & $0.01(0.16)[0.0]$ & $0.01(0.16)[0.0]$ & $0.01(0.16)[0.0]$ & $<0.001$ \\
\hline$\geq 3$ & $0.2 \%(39 / 21,465)$ & $0.1 \%(4 / 2804)$ & $0.2 \%(35 / 18,661)$ & 0.603 \\
\hline AIS face, mean (SD) [median] & $0.37(0.57)[0.0]$ & $0.43(0.61)[0.37]$ & $0.36(0.56)[0.0]$ & $<0.001$ \\
\hline$\geq 3$ & $0.1 \%(22 / 21,465)$ & $0.1 \%(3 / 2804)$ & $0.1 \%(19 / 18,661)$ & $>0.999$ \\
\hline AIS chest, mean (SD) [median] & $0.88(1.4)[0.0]$ & $1.4(1.7)[0.0]$ & $0.80(1.4)[0.0]$ & $<0.001$ \\
\hline$\geq 3$ & $22.1 \%(4745 / 21,465)$ & $34.5 \%(966 / 2804)$ & $20.3 \%(3779 / 18,661)$ & $<0.001$ \\
\hline AIS abdomen, mean (SD) [median] & $0.29(0.86)[0.0]$ & $0.43(1.0)[0.0]$ & $0.27(0.83)[0.0]$ & $<0.001$ \\
\hline$\geq 3$ & $4.6 \%(979 / 21,465)$ & $6.8 \%(191 / 2804)$ & $4.2 \%(788 / 18,661)$ & $<0.001$ \\
\hline AIS upper extremity, mean (SD) [median] & $0.43(0.78)[0.0]$ & $0.56(0.87)[0.0]$ & $0.41(0.76)[0.0]$ & $<0.001$ \\
\hline$\geq 3$ & $1.2 \%(247 / 21,465)$ & $2.1 \%(58 / 2804)$ & $1.0 \%(189 / 18,661)$ & $<0.001$ \\
\hline AIS lower extremity, mean (SD) [median] & $0.75(1.2)[0.0]$ & $0.77(1.2)[0.0]$ & $0.75(1.2)[0.0]$ & 0.315 \\
\hline$\geq 3$ & $18.2 \%(3909 / 21,465)$ & $16.8 \%(470 / 2804)$ & $18.4 \%(3439 / 18,661)$ & 0.033 \\
\hline AIS spine, mean (SD) [median] & $0.69(1.2)[0.0]$ & $1.1(1.3)[0.0]$ & $0.64(1.1)[0.0]$ & $<0.001$ \\
\hline$\geq 3$ & $5.2 \%(1126 / 21,465)$ & $8.5 \%(239 / 2804)$ & $4.8 \%(887 / 18,661)$ & $<0.001$ \\
\hline Exploratory laparotomy & $2.0 \%(424 / 21,465)$ & $3.8 \%(107 / 2804)$ & $1.7 \%(317 / 18,661)$ & $<0.001$ \\
\hline Thoracotomy & $0.2 \%(44 / 21,465)$ & $0.4 \%(10 / 2804)$ & $0.2 \%(34 / 18,661)$ & 0.057 \\
\hline craniotomy/craniectomy & $3.5 \%(741 / 21,465)$ & $3.7 \%(105 / 2804)$ & $3.4 \%(636 / 18,661)$ & 0.363 \\
\hline \multicolumn{5}{|l|}{ Comorbid conditions: } \\
\hline Cardiac disease & $18.3 \%(3874 / 21,222)$ & $16.0 \%(440 / 2750)$ & $18.6 \%(3434 / 18,472)$ & $<0.001$ \\
\hline Pulmonary disease/smoker & $14.7 \%(3114 / 21,222)$ & $14.6 \%(402 / 2750)$ & $14.7 \%(2712 / 18,472)$ & 0.93 \\
\hline Liver disease & $0.6 \%(125 / 21,222)$ & $0.5 \%(14 / 2750)$ & $0.6 \%(111 / 18,472)$ & 0.557 \\
\hline Renal disease/dialysis & $2.0 \%(433 / 21,222)$ & $1.1 \%(31 / 2750)$ & $2.2 \%(402 / 18,472)$ & $<0.001$ \\
\hline Diabetes mellitus & $22.7 \%(4826 / 21,222)$ & $24.0 \%(661 / 2750)$ & $22.5 \%(4165 / 18,472)$ & 0.082 \\
\hline PVD/amputation & $1.0 \%(211 / 21,222)$ & $0.8 \%(21 / 2750)$ & $1.0 \%(190 / 18,472)$ & 0.191 \\
\hline Functionally dependent & $4.1 \%(873 / 21,222)$ & $2.9 \%(80 / 2750)$ & $4.3 \%(793 / 18,472)$ & 0.001 \\
\hline Dementia & $5.9 \%(1254 / 21,222)$ & $4.7 \%(130 / 2750)$ & $6.1 \%(1124 / 18,472)$ & 0.005 \\
\hline CVA & $7.4 \%(1579 / 21,222)$ & $5.9 \%(161 / 2750)$ & $7.7 \%(1418 / 18,472)$ & 0.001 \\
\hline Bleeding disorder & $20.3 \%(4299 / 21,222)$ & $18.5 \%(510 / 2750)$ & $20.5 \%(3789 / 18,472)$ & 0.017 \\
\hline DNR & $6.2 \%(1309 / 21,222)$ & $3.5 \%(97 / 2750)$ & $6.6 \%(1212 / 18,472)$ & $<0.001$ \\
\hline
\end{tabular}

$p$ values were obtained from Chi-square for categorical variables and from a $t$ test for continuous variables

$S B P$ systolic blood pressure; SD standard deviation; GCS Glasgow Coma Scale; ISS Injury Severity Score; AIS Abbreviated Injury Scale; PVD peripheral vascular disease; $C V A$ cerebrovascular accident, $D N R$ do not resuscitate 
Fig. 3 Kaplan-Meier survival curve and survival table for elderly patients ( $>80$ years) according to whether they underwent a TR or not. $T R$ Tracheostomy, AHR Adjusted Hazard Ratio, CI Confidence Interval. $P$ value for the AHR was calculated from a proportional Cox regression model with a time dependent variable

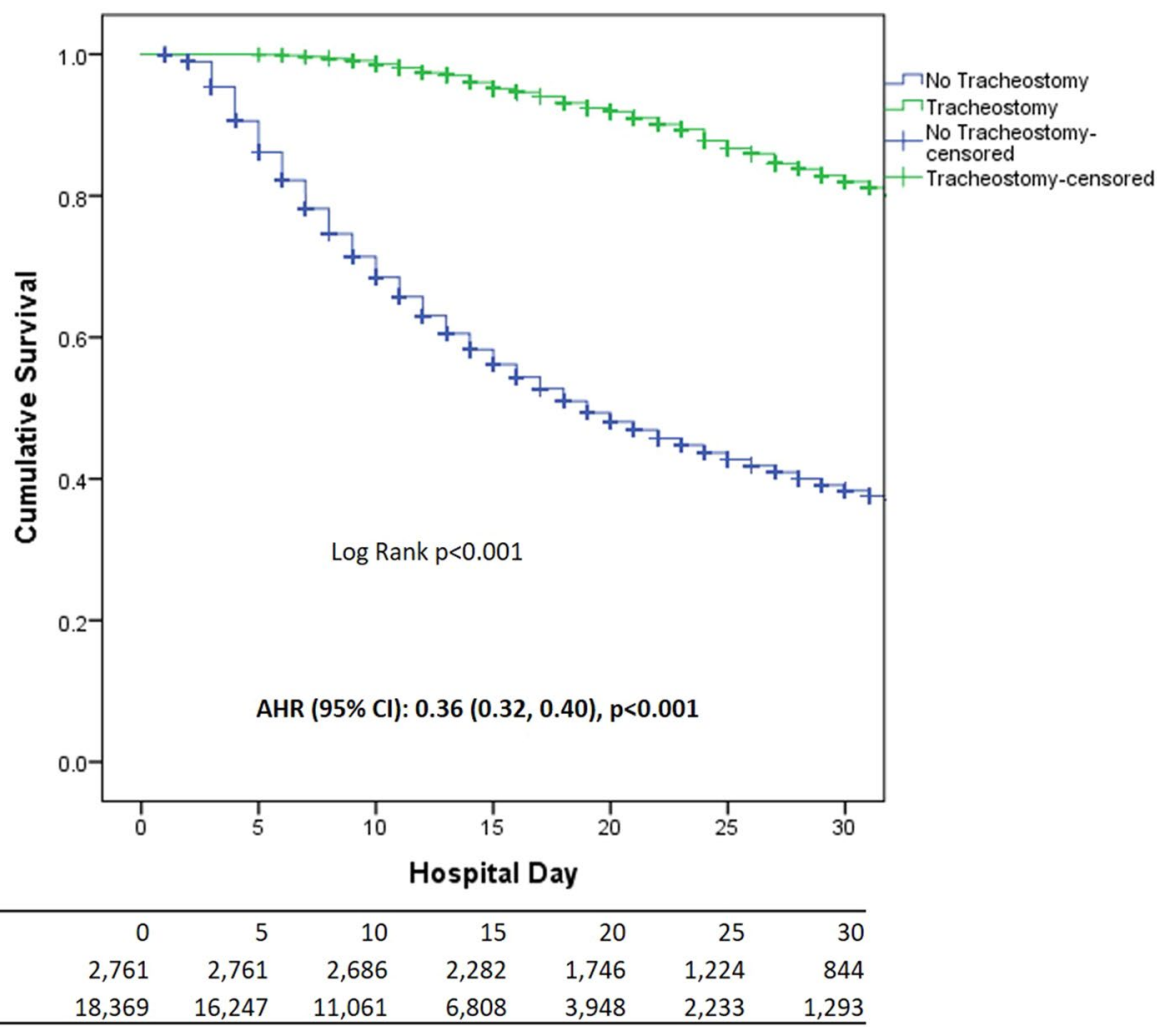

time dependent variable. Nonetheless, other factors could not be accounted for. More specifically, we were unable to discern when the DNR status was decided for these patients, i.e. whether it was upon admission or further along in their hospital course. Given however, the large sample size and the relatively low proportion of patients with DNR status, our results would not have been altered in a meaningful way, even if this factor was accounted for. Impact on the ventilation free days cannot be quantified due to the inability to compare two similar groups of patients. Associated complications directly related to the TR itself, including infection, hemorrhage, tracheal stenosis and pneumothorax [25], were not available. Subsequent functional outcomes and especially, long term outcomes were also unavailable.

Despite these limitations, our large sample size provides a gross estimate of current practices in TR utilization among trauma patients and more specifically, among the elderly. Our findings can be used as the basis to further study eligibility criteria for TR in elderly trauma patients and develop recommendation guidelines for best practices. Furthermore, these results can serve trauma surgeons and intensivists in discussions regarding prognosis and goals of care if a TR is being considered. Lastly, they may be also utilized in the primary care setting when advanced directives are being considered.

In conclusion, tracheostomy is less commonly utilized for elderly trauma patients and this difference has been consistent over last decade. Tracheostomy utilization is associated with a significant survival benefit and delaying or avoiding it in this population predominantly based on age may not be justified.

Author contributions Study conception and design: GB, NKD, KC, Acquisition of data: GB, KC, KAP. Analysis and interpretation of data: GB, KC, NKD. Literature review: KC, GB. Drafting of manuscript: KC, GB, NKD. Critical revision: PN, EJL, DRM, RH.

\section{Compliance with ethical standards}

Conflict of interest The authors have no conflicts of interest to report and have received no financial support in relation to this manuscript.

\section{References}

1. 2014 National Population Projections Tables. United States Census Bureau. 2014. https://www.census.gov. Accessed 16 Mar 2018.

2. Llompart-Pou JA, Pérez-Bárcena J, Chico-Fernández M, SánchezCasado M, Raurich JM. Severe trauma in the geriatric population. World J Crit Care Med. 2017;6(2):99.

3. Kozar RA, Arbabi S, Stein DM, et al. Injury in the aged: geriatric trauma care at the crossroads. J Trauma Acute Care Surg. 2015;78(6):1197-209.

4. National Center fo Injury Prevention and Control. leading_causes_ of_death_age_group_2015_1050w740h.gif $(1050 \times 740)$. https:// 
www.cdc.gov/injury/images/lc-charts/leading_causes_of_death _age_group_2015_1050w740h.gif. Accessed 11 Apr 2018.

5. Mackersie RC. For the Care of the Underserved. J Trauma Acute Care Surg. 2014;77(5):653-9.

6. Baron DM, Hochrieser H, Metnitz PGH, Mauritz W. Tracheostomy is associated with decreased hospital mortality after moderate or severe isolated traumatic brain injury. Wien Klin Wochenschr. 2016;128(11-12):397-403.

7. Nieszkowska A, Combes A, Luyt C-E, et al. Impact of tracheotomy on sedative administration, sedation level, and comfort of mechanically ventilated intensive care unit patients. Crit Care Med. 2005;33(11):2527-2533. https://www.ncbi.nlm.nih.gov/ pubmed/16276177. Accessed 11 Apr 2018.

8. Hyde GA, Savage SA, Zarzaur BL, et al. Early tracheostomy in trauma patients saves time and money. Injury. 2015;46(1):110-4.

9. Mehta AB, Syeda SN, Bajpayee L, Cooke CR, Walkey AJ, Wiener RS. Trends in tracheostomy for mechanically ventilated patients in the United States, 1993-2012. Am J Respir Crit Care Med. 2015;192(4):446-54.

10. Villwock JA, Villwock MR, Deshaies EM. Tracheostomy timing affects stroke recovery. J Stroke Cerebrovasc Dis. 2014;23(5):1069-72.

11. Villwock JA, Jones K. Outcomes of early versus late Tracheostomy: 2008-2010. Laryngoscope. 2014;124(8):1801-6.

12. Young D, Harrison DA, Cuthbertson BH, Rowan K. Effect of early vs late tracheostomy. JAMA. 2013;309(20):2121-9.

13. Alali AS, Scales DC, Fowler RA, et al. Tracheostomy timing in traumatic brain injury. J Trauma Acute Care Surg. 2014;76(1):70-8.

14. Arabi Y, Haddad S, Shirawi N, Al Shimemeri A. Early tracheostomy in intensive care trauma patients improves resource utilization: a cohort study and literature review. Crit Care. 2004;8(5):R347.

15. Christakis NA, Lamont EB. Extent and determinants of error in physicians' prognoses in terminally ill patients: prospective cohort study. West J Med. 2000;172(5):310-313. https://www.ncbi.nlm. nih.gov/pubmed/18751282. Accessed 11 Apr 2018.

16. Brandberg C, Blomqvist $\mathrm{H}$, Jirwe $\mathrm{M}$. What is the importance of age on treatment of the elderly in the intensive care unit? Acta Anaesthesiol Scand. 2013;57(6):698-703.

17. Hennessy D, Juzwishin K, Yergens D, Noseworthy T, Doig C. Outcomes of elderly survivors of intensive care. Chest. 2005;127(5):1764-74.

18. de Rooij SE, Abu-Hanna A, Levi M, de Jonge E. Factors that predict outcome of intensive care treatment in very elderly patients: a review. Crit Care. 2005;9(4):R307. https://doi.org/10.1186/cc353 6.

19. Sacanella E, Pérez-Castejón JM, Nicolás JM, et al. Mortality in healthy elderly patients after ICU admission. Intensive Care Med. 2009;35(3):550-5.

20. Marik PE. Should age limit admission to the intensive care unit? Am J Hosp Palliat Med. 2007;24(1):63-6.

21. Nathanson BH, Higgins TL, Brennan MJ, Kramer AA, Stark M, Teres D. Do elderly patients fare well in the ICU? Chest. 2011;139(4):825-31.

22. Christensen K, Hansen TG, Rasmussen LS. Intensive care units and the oldest-old: are we doing good, too little, or too much? Acta Anaesthesiol Scand. 2013;57(6):681-3.

23. Brunner-Ziegler S, Heinze G, Ryffel M, Kompatscher M, Slany J, Valentin A. Patients in intensive care: prognosis and therapeutic activity. Wien Klin Wochenschr. 2007;119(1-2):14-9.

24. Liu D, Lyu J, Zhao H, An Y. The influence of analgesic-based sedation protocols on delirium and outcomes in critically ill patients: a randomized controlled trial, Colantuoni E, ed. PLoS ONE. 2017;12(9):e0184310.

25. Griffiths J, Barber VS, Morgan L, Young JD. Systematic review and meta-analysis of studies of the timing of tracheostomy in adult patients undergoing artificial ventilation. Br Med $\mathrm{J}$. 2005;330(7502):1243-6. 